\title{
RIGID AND RELAXED DIAGONAL ORBITAL HARDNESSES OF THE VALENCE SHELL OF TRANSITION METAL IONS FROM X $\alpha$ CALCULATIONS*
}

\author{
T. Antonova, N. Neshev, E.I. Proinov \\ Bulgarian Academy of Sciences, Institute of Kinetics and Catalysis \\ 10-40 Sofia, Bulgaria
}

AND R.F. NALEWAJSKI

K. Guminski Department of Theoretical Chemistry, Jagiellonian University M. Karasia 3, 30-060 Kraków, Poland (Received February 15, 1991)

\begin{abstract}
Valence shell diagonal hardnesses (electron repulsion) parameters are reported for the first- and second-row transition metal ions, determined via finite differences from the $\mathrm{X} \alpha$ eigenvalues for alternative configurations and charges. Both rigid (unrelaxed orbitals) and orbitally relaxed hardnesses have been calculated. The relaxed parameters provide a convenient basis for generating a realistic hardness tensor of cataly tic systems involving transition metals at the atoms-in-molecules (AIM) oxidation state and configurations, thus facilitating the charge-sensitivity-analysis of chemisorption systems both at the AIM and orbital resolutions. The observed trends in the orbital relaxation effects are briefly discussed.
\end{abstract}

PACS numbers: $31.10 .+z$

*The work was partially supported by the Kaloyanoff Foundation (Munich) and the research grant No. DNS-P/03/194/90-2 from the Polish Ministry of National Education. 


\section{Introduction}

The molecular charge-sensitivity-analysis (CSA) [1-14], based upon the concepts of global and regional (rigid and relaxed) chemical potentials, hardnesses, softnesses, the Fukui function parameters, and the related energy derivatives, has recently been advocated as an attractive theoretical framework for applications in the theory of chemisorption and catalysis $[11,13]$. This approach has already been successfully applied both qualitatively and quantitatively to selected rules of chemistry $[1,2,4,5,7,9$,$] and trends in the chemical reactivity [4,7,9-17]$. Most of the reporetd applications to large molecular systems adopt the atoms-in-molecules (AIM) resolution, although the orbitally resolved CSA has also been developed at various levels of sofistication [13, 18-22]. Future wider applications of this method would require the realistic AIM (global or orbital) data for alternative oxidation states and orbital configurations, sufficient to generate the canonical AIM chemical potentials and hardness tensor corresponding to the actual valence state of the AIM in the system under consideration, as revealed by the standard SCF MO calculations. Of particular importance is also the inclusion of the orbital relaxation in the derivatives involving electron population variables. The attempts to include such effects in atomic systems, via finite differences and the virial theorem (Fock) scaling, respectively, have recently been reported $[20,23]$ for selected atoms.

Applications of the CSA to model catalytic systems involving clusters of metallic and oxide catalysts would require the detailed knowledge of the valence shell orbital hardnesses for alternative states of transition metal ions, preferably the data including the changes in the orbital exponents due to a removal or addition of electrons from/to the metal atom/ion. One possible source of such parameters, used in the semiempirical AIM CSA [7], are the experimental values of the electron affinity and ionization potential data [14, 24], but they hardly cover the full range of the atomic valence states required for an adequate interpolation; alternatively such data can be calculated theoretically, e. g., using the Hartree-Fock (HF) or the SCF calculations [10-13,17, 19,21], the hyper-HF [20, 25], Kohn-Sham [Local Density Approximation (LDA)] [14, 15], and the $\mathrm{X} \alpha[20,22]$ theories. The latter method $[26,27]$ is especially attractive for this purpose since the first derivatives of the energy, $E=E(n)$, with respect to the canonical orbital occupation numbers, $n=$ $\left(n_{1}, n_{2}, \ldots\right)$, both variational (orbitally relaxed) and partial (orbitally unrelaxed), give the repsective one-electron eigenvalues, $e=\left(e_{1}, e_{2}, \ldots\right)$ :

$$
\left(\delta E / \delta n_{i}\right) n^{\circ}=\left(\partial E / \partial n_{i}\right) n^{\circ}=e_{i}\left(n^{\circ}\right)
$$

here $n^{0}$ specifies the atom electron configuration. This feature allows one to determine the approximate estimates of the relaxed hardness (electron repulsion) derivatives:

$$
\eta_{i j}^{\mathrm{rel}}\left(n^{\circ}\right)=\left(\delta^{2} E / \delta n_{i} \delta n_{j}\right) n^{\circ}=\left(\delta e_{i} / \delta n_{j}\right) n_{\circ}=\left(\delta e_{j} / \delta n_{i}\right) n^{\circ},
$$

via finite differences from the known $\mathrm{X} \alpha$ eigenvalues. The corresponding partial second derivatives determine the orbitally unrelaxed (rigid) hardnesses:

$$
\eta_{i j}^{\text {unrel }}\left(n^{\circ}\right)=\left(\partial^{2} E / \partial n_{i} \partial n_{j}\right) n^{\circ}=\left(\partial e_{i} / \partial n_{j}\right) n^{\circ}=\left(\partial e_{j} / \partial n_{i}\right) n^{\circ} \neq \eta_{i j}^{\text {rel }}\left(n^{\circ}\right) .
$$


It is the main purpose of the present work to report the relaxed and unrelaxed diagonal $\left(\eta_{i i}\right)$ hardnesses of transition metal ions (first- and second-row) from X $\alpha$ calculations. The reported results have been generated for future applications of the CSA to catalytic systems.

\section{Calculations and results}

The unrelaxed hardnesses, calculated directly within the standard $\mathrm{X} \alpha$ program, have been obtained from the usual expression [26]:

$$
\eta_{i i}^{\text {unrel }}\left(n^{0}\right) \equiv J_{i}^{\text {unrel }}\left(n^{\circ}\right)=F_{i i}^{0}-2 \alpha\left(\frac{3}{8 \pi}\right)^{1 / 3} \int \varrho_{i}^{2}(r)\left[\sum_{j} n_{j}^{\circ} \varrho_{j}(r)\right]^{-2 / 3} \mathrm{~d} r
$$

where the familiar Slater integral $F_{i i}^{0}$ accounts for the Coulomb contribution to the hardness while the second integral represents the local approximation of the exchange part; here $\varrho_{i}(r)$ stands for the orbital probability density and $\alpha$ is the method adjustable parameter scaling the exchange interactions $[14,26]$.

The following simplest finite-difference estimate of the relaxed diagonal hardness has been adopted in the present study:

$$
\eta_{i i}^{\mathrm{rel}}\left(\dot{n}^{\circ}\right) \equiv J_{i}^{\mathrm{rel}}\left(n^{\circ}\right) \approx \frac{1}{\Delta n}\left[e_{i}\left(n^{\circ}\right)-e_{i}\left(n_{i}\right)\right]
$$

where $\Delta n=1 / 2$ and the shifted occupancy vector $n_{i}=\left(n_{i}^{\circ}, n_{2}^{\circ}, \ldots, n_{i}^{\circ}-\Delta n, \ldots\right)$ involves a removal of $\Delta n$ electrons from the $i$-th orbital only relative to $n^{\circ}$.

The results for the first- and second-row transition metals are listed in Table I. In Fig. 1 we examine the resulting trends in the magnitude of the orbital relaxation effects, measured by the $J_{i}^{\text {rel }} / J_{i}^{\text {unrel }}$ ratio, for the oxidation states and configurations considered in Table I.

The experimental approximations of the orbital hardnesses for a given oxidation state $q$ can be generated via the familiar Pariser [28] finite difference formula:

$$
\eta_{i i}^{\exp }(q) \approx I_{i}(q)-I_{i}(q-1)
$$

for the relevant electron configurations; here $I_{i}$ is the corresponding orbital ionization potential $\left(I_{i}(q-1)=A_{i}(q)\right.$ is the corresponding orbital electron affinity). The so-called Valence State Ionization Energies (VSIE) developed for the Self Consitent Charge and Configuration Molecular Orbital Theory [29], via an interpolation of the average atomic spectroscopic data, can be used to approximate the valence orbital ionization potentials (electron affinities).

In Table II we compare the $\mathrm{X} \alpha$ relaxed orbital hardnesses with the corresponding experimental estimates from Eq. (6) and the VSIE, for the first-row transition metals. A graphical representation of this comparison is shown in Fig. 2. 
TABLE I

The $\mathrm{X} \alpha$ valence shell hardnesses of transition metal ions (in eV).

\begin{tabular}{|c|c|c|c|c|c|}
\hline \multirow[t]{2}{*}{ element } & \multicolumn{2}{|c|}{$n_{i}^{i}$} & & \multirow[t]{2}{*}{$J_{i}^{\text {unrel }}$} & \multirow[t]{2}{*}{$\overline{J_{i}^{\text {rel }}}$} \\
\hline & $d d$ & $4 s$ & & & \\
\hline $\mathrm{Ti}^{0}$ & $\begin{array}{l}2 \\
2\end{array}$ & $\begin{array}{l}2 \\
2\end{array}$ & $\begin{array}{l}3 d \\
4 s\end{array}$ & $\begin{array}{r}15.780 \\
6.410\end{array}$ & $\begin{array}{r}10.808 \\
5.735\end{array}$ \\
\hline $\mathrm{Ti}^{+1}$ & $\begin{array}{l}2 \\
2\end{array}$ & $\begin{array}{l}1 \\
1\end{array}$ & $d d$ & $\begin{array}{r}16.450 \\
6.860\end{array}$ & $\begin{array}{r}12.759 \\
6.395\end{array}$ \\
\hline $\mathrm{Ti}^{+2}$ & 2 & 0 & $3 d$ & 17.230 & 14.416 \\
\hline $\mathrm{Ti}^{+3}$ & 1 & 0 & $3 d$ & 19.330 & 17.134 \\
\hline $\mathrm{V}^{0}$ & $\begin{array}{l}3 \\
3\end{array}$ & $\begin{array}{l}2 \\
2\end{array}$ & $3 d$ & $\begin{array}{r}17.560 \\
6.730\end{array}$ & $\begin{array}{r}11.463 \\
6.024\end{array}$ \\
\hline $\mathrm{V}^{+1}$ & $\begin{array}{l}3 \\
3\end{array}$ & $\begin{array}{l}1 \\
1\end{array}$ & $\begin{array}{l}3 d \\
4 s\end{array}$ & $\begin{array}{r}18.100 \\
7.230\end{array}$ & $\begin{array}{r}13.404 \\
6.729\end{array}$ \\
\hline $\mathrm{V}^{+2}$ & 3 & 0 & $3 d$ & 18.760 & 15.047 \\
\hline $\mathrm{V}^{+3}$ & 2 & 0 & $3 d$ & 20.760 & 20.052 \\
\hline $\mathrm{Cr}^{0}$ & $\begin{array}{l}5 \\
5\end{array}$ & $\begin{array}{l}1 \\
1\end{array}$ & $\begin{array}{l}3 d \\
4 s\end{array}$ & $\begin{array}{r}17.200 \\
6.460\end{array}$ & $\begin{array}{l}9.922 \\
5.726\end{array}$ \\
\hline $\mathrm{Cr}^{+1}$ & 5 & 0 & $3 d$ & 17.940 & 12.154 \\
\hline $\mathrm{Cr}^{+2}$ & 4 & 0 & $3 d$ & 20.230 & 15.673 \\
\hline $\mathrm{Cr}^{+3}$ & 3 & 0 & $3 d$ & 22.170 & 18.419 \\
\hline $\mathrm{Cr}^{+4}$ & 2 & 0 & $3 d$ & 23.860 & 20.713 \\
\hline $\mathrm{Cr}^{+5}$ & 1. & 0 & $3 d$ & 25.390 & 22.779 \\
\hline $\mathrm{Mn}^{0}$ & $\begin{array}{l}5 \\
5\end{array}$ & $\begin{array}{l}2 \\
2\end{array}$ & $4 s$ & $\begin{array}{r}20.780 \\
7.310\end{array}$ & $\begin{array}{r}12.666 \\
6.541\end{array}$ \\
\hline $\mathrm{Mn}^{+1}$ & $\begin{array}{l}5 \\
5\end{array}$ & $\begin{array}{l}1 \\
1\end{array}$ & $4 s$ & $\begin{array}{r}21.170 \\
7.870\end{array}$ & $\begin{array}{r}14.652 \\
7.341\end{array}$ \\
\hline $\mathrm{Mn}^{+2}$ & 5 & 0 & $3 d$ & 21.680 & 16.304 \\
\hline $\mathrm{Mn}^{+3}$ & 4 & 0 & sa & 23.560 & 19.059 \\
\hline $\mathrm{Mn}^{+4}$ & 3 & 0 & $3 d$ & 25.230 & 21.396 \\
\hline $\mathrm{Fe}^{0}$ & $\begin{array}{l}6 \\
6\end{array}$ & 2 & $4 s$ & $\begin{array}{r}22.290 \\
7.570\end{array}$ & $\begin{array}{r}13.253 \\
6.778\end{array}$ \\
\hline $\mathrm{Fe}^{+1}$ & $\begin{array}{l}6 \\
6\end{array}$ & 1 & $4 s$ & $\begin{array}{r}22.630 \\
8.160\end{array}$ & $\begin{array}{r}15.256 \\
7.592\end{array}$ \\
\hline
\end{tabular}


Rigid and Relaxed Diagonal Orbital Hardnesses ...

TABLE I (cont.)

\begin{tabular}{|c|c|c|c|c|c|}
\hline \multirow[t]{2}{*}{$\overline{\text { element }}$} & \multicolumn{2}{|c|}{$\overline{n_{i}^{0}}$} & \multirow[t]{2}{*}{$\bar{i}$} & \multirow[t]{2}{*}{$\bar{J}_{i}^{\text {unrel }}$} & \multirow[t]{2}{*}{$\overline{J_{i}^{\text {rel }}}$} \\
\hline & $\overline{3 d}$ & $4 s$ & & & \\
\hline $\mathrm{Fe}^{+2}$ & 6 & 0 & $\overline{3 d}$ & 23.090 & 16.919 \\
\hline $\mathrm{Fe}^{+3}$ & 5 & 0 & $3 d$ & 24.940 & 19.695 \\
\hline \multirow[t]{2}{*}{$\mathrm{Co}^{\circ}$} & 7 & 2 & $3 d$ & 23.750 & 13.805 \\
\hline & 7 & 2 & $4 s$ & 7.820 & 6.746 \\
\hline \multirow[t]{2}{*}{$\mathrm{Co}^{+1}$} & 7 & 1 & $3 d$ & 24.060 & 15.846 \\
\hline & 7 & 1 & $4 s$ & 8.450 & 7.896 \\
\hline $\mathrm{Co}^{+2}$ & 7 & 0 & $3 d$ & 24.490 & 17.532 \\
\hline $\mathrm{Co}^{+3}$ & 6 & 0 & $3 d$ & 26.300 & 20.319 \\
\hline \multirow[t]{2}{*}{$\mathrm{Cu}^{0}$} & 10 & 1 & $3 d$ & 24.830 & 12.880 \\
\hline & 10 & 1 & $4 s$. & 7.570 & 6.860 \\
\hline $\mathrm{Cu}^{+1}$ & 9 & 0 & $3 d$ & 25.250 & 15.211 \\
\hline $\mathrm{Cu}^{+2}$ & 8 & 0 & $3 d$ & 27.220 & 18.710 \\
\hline \multirow[t]{2}{*}{$\mathrm{Ni}^{0}$} & 8 & 2 & $3 d$ & 25.180 & 14.345 \\
\hline & 8 & 2 & $4 s$ & 8.060 & 7.227 \\
\hline \multirow[t]{2}{*}{$\mathrm{Ni}^{+1}$} & 8 & 1 & $3 d$ & 25.470 & 16.421 \\
\hline & 8 & 1 & $4 s$ & 8.720 & 8.160 \\
\hline $\mathrm{Ni}^{+2}$ & 8 & 0 & $3 \dot{d}$ & 25.870 & 18.125 \\
\hline $\mathrm{Ni}^{+3}$ & 7 & 0 & $3 d$ & 27.650 & 23.610 \\
\hline \multirow[t]{2}{*}{$\mathrm{Zn}^{0}$} & 10 & 2 & $3 d$ & 27.970 & 15.379 \\
\hline & 10 & 2 & $4 s$ & .530 & 7.643 \\
\hline \multirow[t]{2}{*}{$\mathrm{Zn}^{+1}$} & 10 & 1 & $3 d$ & 28.230 & 17.080 \\
\hline & 10 & 1 & $4 s$ & 9.250 & 8.663 \\
\hline \multirow[t]{2}{*}{$\mathrm{Zn}^{+2}$} & 10 & 0 & $3 d$ & 28.580 & 19.296 \\
\hline & $4 d$ & $5 s$ & & & \\
\hline \multirow[t]{2}{*}{$Y^{0}$} & 1 & 2 & $\overline{4 d}$ & 9.260 & 7.333 \\
\hline & 1 & 2 & $5 s$ & 5.610 & 4.986 \\
\hline \multirow[t]{2}{*}{$\mathrm{Y}^{+1}$} & 1 & 1 & $4 d$ & 10.070 & 8.812 \\
\hline & 1 & 1 & $5 s$ & 5.980 & 5.569 \\
\hline $\mathrm{Y}^{+2}$ & 1 & 0 . & $4 d$ & 10.800 & 9.967 \\
\hline \multirow[t]{2}{*}{$\mathrm{Zr}^{0}$} & 2 & 2 & $4 d$ & 10.780 & 8.055 \\
\hline & 2 & 2 & $5 s$ & 5.970 & 5.305 \\
\hline
\end{tabular}


TABLE I (cont.)

\begin{tabular}{|c|c|c|c|c|c|}
\hline \multirow[t]{2}{*}{ element } & \multicolumn{2}{|c|}{$n_{i}^{\circ}$} & \multirow[t]{2}{*}{$i$} & \multirow[t]{2}{*}{$J_{i}^{\text {unrel }}$} & \multirow[t]{2}{*}{$J_{i}^{\text {rel }}$} \\
\hline & $4 d$ & $5 s$ & & & \\
\hline \multirow[t]{2}{*}{$\mathrm{Zr}^{+1}$} & 2 & 1 & $\overline{4 d}$ & 11.350 & 9.465 \\
\hline & 2 & 1 & $5 s$ & 6.380 & 5.909 \\
\hline $\mathrm{Zr}^{+2}$ & 2 & 0 & $4 d$ & 11.930 & 10.600 \\
\hline $\mathrm{Zr}^{+3}$ & 1 . & 0 & $4 d$ & 12.990 & 10.650 \\
\hline \multirow[t]{2}{*}{$\mathrm{Nb}^{0}$} & 4 & 1 & $4 d$ & 11.190 & 7.829 \\
\hline & 4 & 1 & $5 s$ & 5.880 & 3.770 \\
\hline $\mathrm{Nb}^{+1}$ & 4 & 0 & $4 d$ & 11.790 & 9.372 \\
\hline $\mathrm{Nb}^{+2}$ & 3 & 0 & $4 d$ & 12.990 & 11.213 \\
\hline $\mathrm{Nb}^{+3}$ & 2 & 0 & $4 d$ & 13.980 & 12.618 \\
\hline $\mathrm{Nb}^{+4}$ & 1 & 0 & $4 d$ & 14.830 & 13.769 \\
\hline \multirow[t]{2}{*}{$\mathrm{Mo}^{\circ}$} & 5 & 1 & $4 d$ & 12.390 & 8.502 \\
\hline & 5 & 1 & $5 s$ & 6.090 & 5.440 \\
\hline $\mathrm{Mo}^{+1}$ & 5 & 0 & $4 d$ & 12.890 & 10.021 \\
\hline $\mathrm{Mo}^{+2}$ & 4 & 0 & $4 d$ & 14.000 & 11.810 \\
\hline $\mathrm{Mo}^{+3}$ & 3 & 0 & $4 d$ & 14.940 & 13.200 \\
\hline $\mathrm{Mo}^{+4}$ & 2 & 0 & $4 d$ & 15.760 & 14.356 \\
\hline $\mathrm{Mo}^{+5}$ & 1 & 0 & $4 \dot{d}$ & 16.500 & 15.360 \\
\hline \multirow[t]{2}{*}{$\mathrm{Tc}^{0}$} & 6 & 1 & $4 d$ & 13.500 & 9.122 \\
\hline & 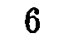 & 1 & $5 s$ & 6.270 & 5.653 \\
\hline $\mathrm{Tc}^{+1}$ & 6 & 0 & $4 d$ & 13.920 & 10.640 \\
\hline $\mathrm{Tc}^{+2}$ & 5 & 0 & $4 d$ & 14.970 & 12.393 \\
\hline $\mathrm{Tc}^{+3}$ & 4 & 0 & $4 d$ & 15.870 & 13.774 \\
\hline $\mathrm{Tc}^{+4}$ & 3 & 0 & $4 d$ & 16.670 & 15.944 \\
\hline $\mathrm{Tc}^{+5}$ & 2 & 0 & $4 d$ & 17.390 & 16.856 \\
\hline
\end{tabular}


TABLE I (cont.)

\begin{tabular}{|c|c|c|c|c|c|}
\hline \multirow[t]{2}{*}{ element } & \multicolumn{2}{|c|}{$n_{i}^{0}$} & \multirow[t]{2}{*}{$\bar{i}$} & \multirow[t]{2}{*}{$J_{i}^{\text {unrel }}$} & \multirow[t]{2}{*}{$\bar{J}_{i}^{\mathrm{rel}}$} \\
\hline & $\overline{4 d}$ & $5 s$ & & & \\
\hline $\mathrm{Ru}^{0}$ & 7 & 2 & $\overline{4 d}$ & 14.550 & 9.705 \\
\hline $\mathbf{R u}^{+1}$ & 7 & 1 & $4 d$ & 14.910 & 11.237 \\
\hline $\mathrm{Ru}^{+2}$ & 7 & 0 & $4 d$ & 15.920 & 12.965 \\
\hline $\mathrm{Ru}^{+3}$ & 6 & 0 & $4 d$ & 16.790 & 14.337 \\
\hline $\mathrm{Ru}^{+4}$ & 5 & 0 & $4 d$ & 17.570 & 15.496 \\
\hline $\mathrm{Ru}^{+5}$ & 4 & 0 & $4 d$ & 18.280 & 16.516 \\
\hline $\mathbf{R u}^{+6}$ & 3 & 0 & $4 d$ & 18.930 & 17.437 \\
\hline$R h^{0}$ & 8 & 1 & $4 d$ & 15.550 & 10.258 \\
\hline & 8 & 1 & $5 s$ & 6.580 & 6.006 \\
\hline $\mathrm{Rh}^{+1}$ & 8 & 0 & $4 d$ & 15.870 & 11.815 \\
\hline $\mathrm{Rh}^{+2}$ & 7 & 0 & $4 d$ & 16.840 & 13.525 \\
\hline $\mathrm{Rh}^{+3}$ & 6 & 0 & $4 d$ & 17.680 & 14.893 \\
\hline $\mathrm{Rh}^{+4}$ & 5 & 0 & $4 d$ & 18.450 & 16.054 \\
\hline $\mathrm{Rh}^{+5}$ & 4 & 0 & $4 d$ & 19.140 & 17.080 \\
\hline $\mathbf{P d}^{0}$ & 10 & 0 & $4 d$ & 15.680 & 10.002 \\
\hline $\mathrm{Pd}^{+1}$ & 9 & 0 & $4 d$ & 16.800 & 12.379 \\
\hline $\mathrm{Pd}^{+2}$ & 8 & 0 & $4 d$ & 17.770 & 14.074 \\
\hline $\mathrm{Pd}^{+3}$ & 7 & 0 & $4 d$ & 18.560 & 15.440 \\
\hline $\mathrm{Pd}^{+4}$ & 6 & 0 & $4 d$ & 19.310 & 16.606 \\
\hline $\mathrm{Ag}^{0}$ & 10 & 1 & $4 d$ & 17.460 & 11.300 \\
\hline & 10 & 1 & $5 s$ & 6.830 & 6.290 \\
\hline $\mathrm{Ag}^{+1}$ & 10 & 0 & $4 d$ & 17.710 & 12.930 \\
\hline $\mathrm{Ag}^{+2}$ & 9 & 0 & $4 d$ & 18.620 & 14.617 \\
\hline
\end{tabular}


TABLE II .

A comparison between the $\mathrm{X} \alpha$ relaxed orbital hardnesses and the finite difference estimates (Pariser formula) from the VSIE (eV) for the first-row transition metals*.

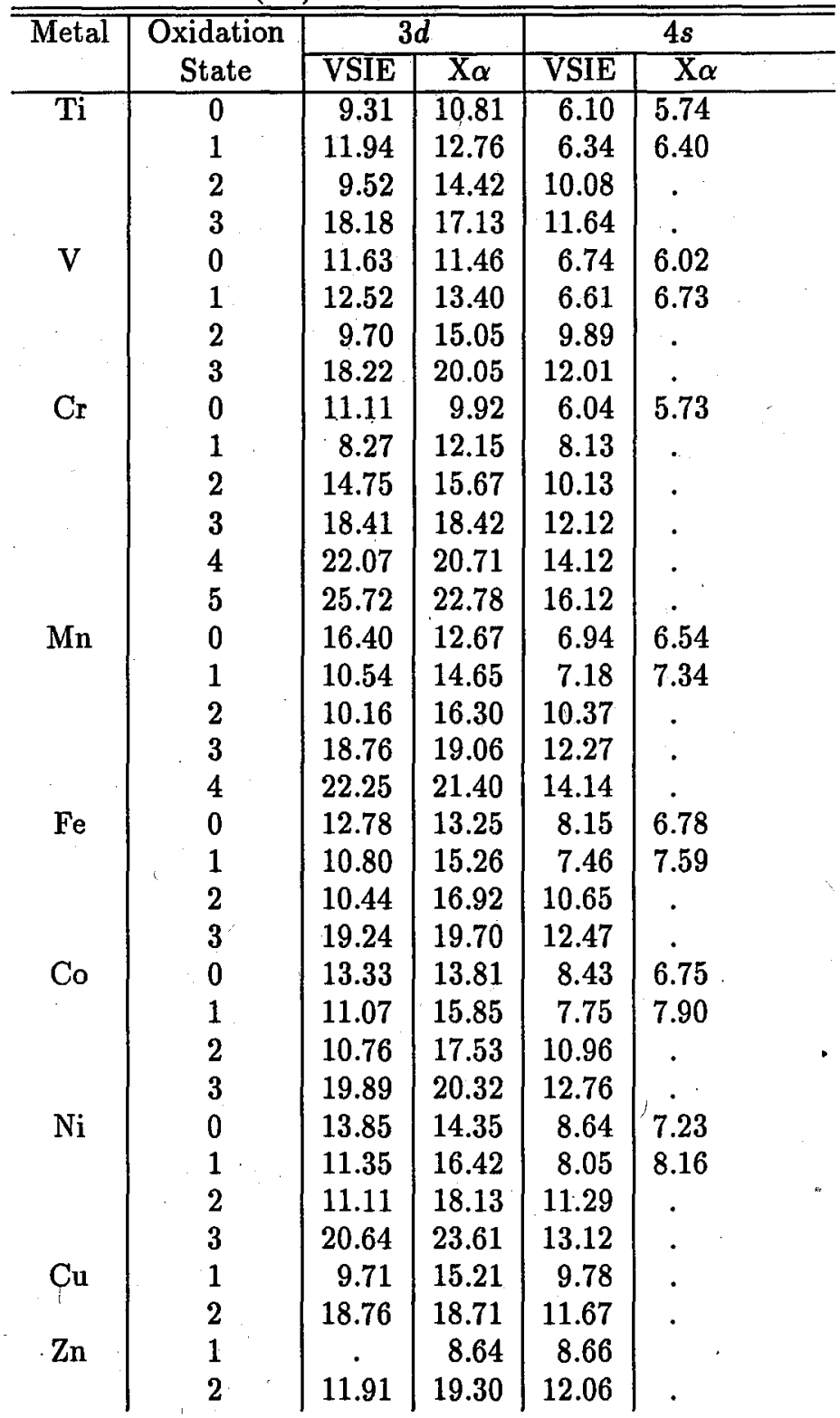

*See Table I for the specification of the electronic configurations. The VSIE of the $4 \mathrm{~s}$ orbital at the higher oxidation states have been calculated from the interpolation formulae [29] for the $d^{n-1} s$ configurations. 


\section{Discussion}

It follows from Fig. 1 that the magnitude of the $s$-type relaxed hardness, relative to the corresponding rigid hardness value, $x_{n l}(q) \equiv J_{n l}^{\text {rel }}(q) / J_{n l}^{\text {unrel }}(q)$, is predicted to remain approximately constant $(\sim 90 \%)$ within the $\mathrm{X} \alpha$ model, for all transition metals considered in the present study. This ratio is slightly higher ( $93 \%)$ for the positive ions $(q=1)$ due to a "harder" orbital electron distribution for a less screened nucleus. The unexpectedly low $x_{5}$ value for $\mathrm{Nb}$ is probably an artefact of a very approximate nature of the numerical differentiation of Eq. (5). It also follows from Fig. 1 that the relaxational lowering of the hardness value in the $d$-type orbitals is much higher than that observed for $s$-type orbitals, ranging from $20-45 \%$ for neutral atoms.

A reference to Fig. 1 also shows that the $x_{n d}$ ratios from the $\mathrm{X} \alpha$ calculations exhibit a slightly decreasing trend across a given row of transition metals. A comparison of the $x_{n d}$ values for the elements in the same group of the periodic table also reveals that in most cases $x_{3 d}(q)<x_{4 d}(q)$; also, for a given element, $x_{n d}(q)<x_{n d}(q+1)$. The observed deviations from these general characteristics can certainly be attributed partly to the changing configurations, leading to variations in the nuclear charge shielding; they are also partly the artefacts of the finite difference procedure adopted in this work. Since a higher $x_{n l}$ value reflects a lower orbital relaxation lowering of the hardness, i.e. a "harder", less polarizable electron distribution, we conclude that the $\mathrm{X} \alpha$ model predicts a slight relative hardening of the $n d$ electrons across a given row of transition metals, and a relative softening of the $\varrho_{n d}$ when going from the first to the second row of transition metals. Such a relative hardening of the electron distribution is also observed when going to higher oxidation states, as one would expect intuitively on the basis of simple nuclear screening considerations.

However, as can be seen in Table II, the $\eta_{i i}$ values from the VSIE are often lower for $q=1,2$ than those for $q=0$, particularly for $d$ orbitals. These deviations are represented in Fig. 2 by the cluster of points deviating most from the otherwise satisfactory correlation between the hardnesses from the $\mathrm{X} \alpha$. and VSIE sources. In general the agreement for $s$ orbitals is better than that observed for $d$ orbitals. It should be stressed that both estimates use different $\Delta n$ in the finite difference procedure: $\Delta n=1 / 2$ in Eq. (5) (one numerical differentiation) and $\Delta n= \pm 1$ in Eq. (6) (two numerical differentiations), and different configuration averaging.

The full AIM modeling of the hardness tensor would also require the corresponding collection of the off-diagonal hardnesses $\eta_{i j}^{\text {rel }}$ for the valence shell orbitals and different oxidation states. Such parameters can in principle be generated using a similar finite difference approach based upon either the $\mathrm{X} \alpha$ calculations or experimental spectroscopic data for atomic systems. Alternatively one can transform the known molecular orbital (MO) hardness tensor, already reflecting the actual valence states of constituent atoms, to the AIM representation [13, 18]. The latter approach is strongly recommended when the CSA follows the standard SCF MO calculations for molecular systems. 


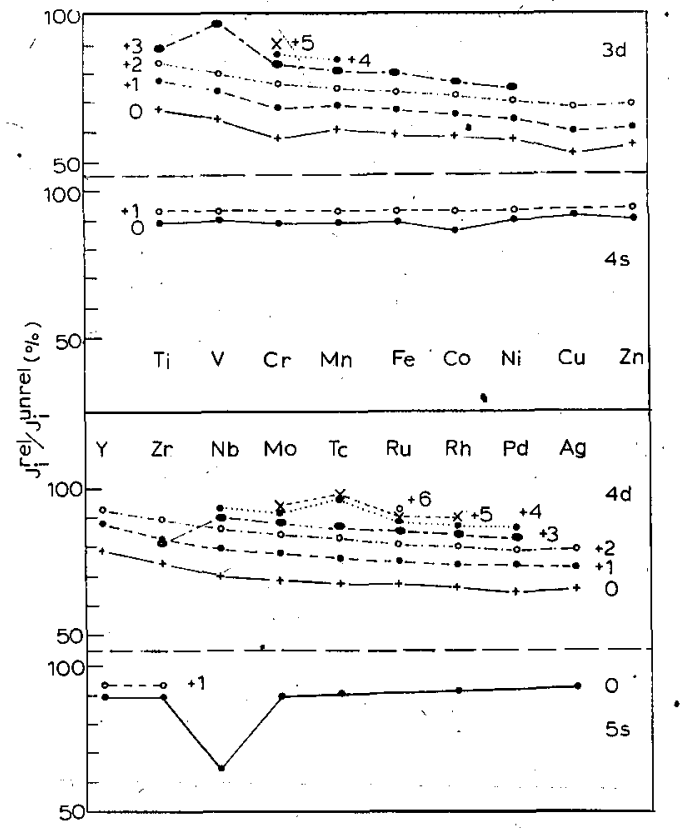

Fig. 1. Plots of the $x_{i}=J_{i}^{\text {rel }} / J_{i}^{\text {unrel }}$ ratios (in \%) from the data of Table I for the valence shell $d$ and $s$ orbitals of transition metal atoms and ions; see Table I for specifications of the relevant electron configurations.

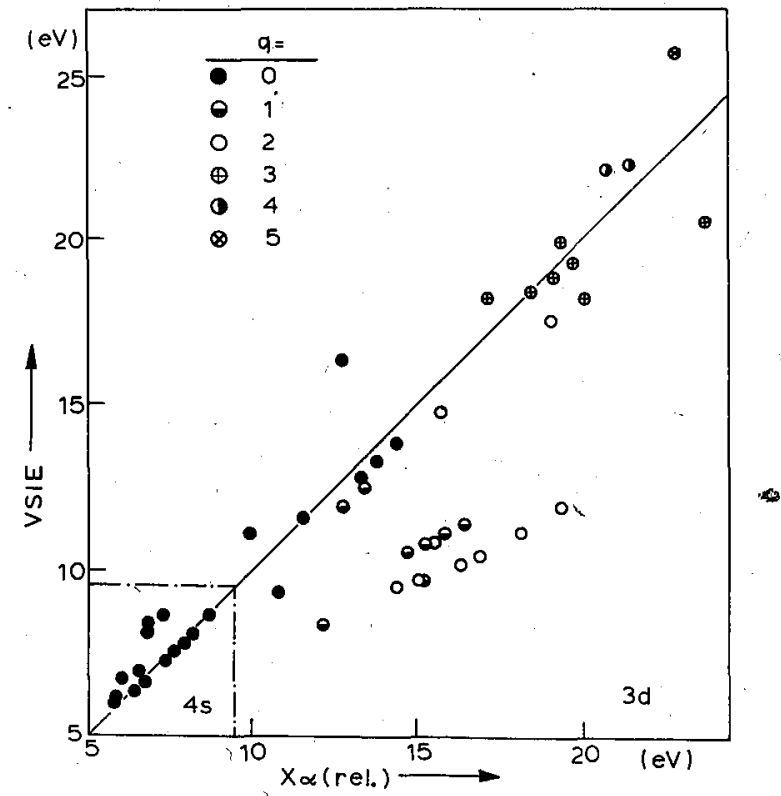

Fig. 2. A graphical comparison between the relaxed orbital hardnesses from the $\mathrm{X} \alpha$ calculations (Table I) and the VSIE hardness estimates (Table II), for the first-row transition metals. 


\section{References}

[1] R.F. Nalewajski, J. Am. Chem. Soc. 106, 944 (1984).

[2] R.F. Nalewajski, J. Phys. Chem. 89, 2831 (1985).

[3] R.F. Nalewajski, ibid. 93, 2658 (1989).

[4] R.F. Nalewajski, in: Proc. Internat. Symposium on Dynamics of Systems with Chemical Reactions, ed. J. Popielawski, World Scientific, Singapore 1989, p. 325, and Refs. therein.

[5] R.F. Nalewajski, M. Koniński, J. Phys. Chem. 88, 6234 (1984).

[6] R.F. Nalewajski, M. Koniński, Acta Phys. Pol. A74, 255 (1988).

[7] R.F. Nalewajski, ibid. A77, 817 (1990).

[8] R.F. Nalewajski, Int. J. Quantum Chem. 40, 265 (1991); ibid. (in press).

[9] R.F. Nalewajski, J. Korchowiec, Z. Zhou, Int. J. Quant. Chem. Symp. 22, 349 (1988).

[10] R.F. Nalewajski, J. Korchowiec, submitted to Chem. Phys; Croat. Chem. Acta 62, 603 (1989).

[11] R.F. Nalewajski, J. Korchowiec, J. Mol. Catal. 54, 324 (1989).

[12] R.F. Nalewajski, J. Korchowiec, Acta Phys. Pol. A76, 747 (1989).

[13] R.F. Nalewajski, J. Korchowiec, J. Mol. Catal. 68, 123 (1991).

[14] R.G. Parr, W. Yang, Density Functional Theory of Atoms and Molecules, Oxford University Press, New York 1989, and Refs. therein.

[15] J.L. Gázquez, A. Vela, M. Galván, Structure and Bonding 66, 79 (1987).

[16] R.G. Parr, W. Yang, J. Am. Chem. Soc. 106, 4049 (1984); W. Yang, R.G. Parr, Proc. Natl. Acad. Sci. USA 82, 6273 (1985).

[17] C. Lee, W. Yang, R.G. Parr, J. Mol. Struct. (Theochem) 163, 305 (1988).

[18] R.F. Nalewajski, J. Mrozek, submitted to Int. J. Quantum Chem.

[19] L. Komorowski, J. Lipiński, submitted to J. Mol. Struct.

[20] J.L. Gázquez, E. Ortiz, J. Chem. Phyṣ. 81, 2741 (1984).

[21] M. Giambiagi, M.S. Giambiagi, J.M. Pires, Chem. Phys. Letl.152, 222 (1988); J. Mol. Struct. (Theochem) (in press).

[22] N.M. Neshev, E.I. Proinov, Proc. 6th Internat. Symposium on Heterogeneous Catalysis, Sofia 1987, Part I, p. 342.

[23] M. Streszewski, R.F. Nalewajski, Int. J. Quantum Chem. 38, 853 (1990).

[24] R.G. Parr, R.G. Pearson, J. Am. Chem. Soc. 105, 7512 (1983).

[25] J. C. Slater, J.B. Mann, T.M. Wilson, J.H. Wood, Phys. Rev.' 184, 672 (1969).

[86] J.C. Slater, Quantum Theory of Molecules and Solids, Vol. 4, McGraw Hill, New York 1974.

[27] A.K. Rajagopal, Adv. Chem. Phys. 6, 587 (1980), and Refs. therein.

[28] R. Pariser, J. Chem. Phys. 21, 568 (1953); see also Ref. 24.

[29] C. J. Ballhausen, H.B. Gray, Molecular Orbital Theory, Benjamin, New York 1965, p. 120; A. Gołębiewski, Chemia Kwantowa Zwiazków Nioeorganicznych, Państwowe Wydawnictwo Naukowe, Warszawa 1969, p. 457, (in Polish). 